American Journal of Pharmacology and Toxicology 3 (1): 4-13, 2008

ISSN 1557-4962

(C) 2008 Science Publications

\title{
Hormetic Triggers for Intervention in Aging, Disease and Trauma
}

\author{
Joan Smith Sonneborn, Professor Emeritus \\ Department of Zoology and Physiology, University of Wyoming, Laramie, Wyoming, 82071
}

\begin{abstract}
Hormesis refers to the ability of a chemical or physical agent to condition the physiological state of an organism to tolerate stress with low doses of otherwise harmful agents. Evolutionary evidence shows that the survival and longevity of species hinge on their optimal ability to resist stress challenge. Hormesis is a potent strategy to stimulate latent repair processes to tolerate a specific challenge. Examples of hormetic agent-mimetics, which induce at least partial physiological conditioning, activate known pathways of longevity determinants, i.e., genetic stability, altered metabolism, immunoregulation and stress resistance. Despite the diversity of age-related diseases, glucose and oxidation-mediated protein and DNA damage are common denominators. The associated physiological conditioning-benefits may trigger: 1) activation of latent stress resistance pathways of youthful DNA repair; 2) increased resistance to oxidizing pollutants; 3 ) improved protein structure and function; 4) improved immunity; 5) damaged tissue remodeling; 6) adjustments in central and peripheral nervous systems; 7) altered metabolism; and 8) delay or breaking of inappropriate protein cross-links. Hormetic mimetics have intervention potential in cancer, diabetes, age-related diseases, infectious diseases, heart and kidney failure, cardiovascular diseases and Alzheimer's disease. Small nucleotide SOS signals, dipeptides, ethanol, thiols, and metals and conserved peptide sequences found in sharks, frogs, woodchucks, and bears, can regulate cytokines, cellular immunity, and central and peripheral neuronal regulatory pathways to promote healthy blood pressure maintenance, heart rate, and metabolic pathways. disease sensitivity. Conserved stress mimetics are highlighted here that rejuvenate DNA and proteins repair and thus may intervene in aging, disease, and trauma. Hibernation Induction Trigger mimetics, Deltorphins, emerge as novel hormetic agents, effective both as pre and post exposure to physiological conditioners to tolerate stress, and prevent damage, and delay possibly aging. Hormesis mimetics offer powerful survival strategies, with better control over the beneficial dose response. Combinations of several mimetics may more closely mimic environmental challenges, which stimulate multiple stress responses.
\end{abstract}

Key words: Mimetics, aging, radiation, diet restriction, hibernation

\section{INTRODUCTION}

Hans Seyle emphasized that we must be guided by the principle to learn to imitate-and if necessary to correct and complement-the body's own molecular mechanisms used to combat the stress factor in disease ${ }^{[1]}$. Metabolic pathways conserved throughout evolution are likely biologically important survival strategies. There is increasing evidence that survival mechanisms found in primitive organisms may be conserved as latent pathways in higher organisms which could be activated with the appropriate molecular triggers to promote physiological hormesis. The identification and use of molecular mimics of stress to access molecular pathways for survival represents a major strategy for disease prevention, recovery, longevity and survival in man. Candidate pharmaceutical agents which imitate the physical and environmental SOS signals to activate complete or partial molecular cascades common to heat, radiation, diet restriction, cell immunity and trauma have been identified and are reviewed below for intervention in aging, disease and trauma. In concert with the integration of the concepts of adaptive response and preconditioning stress within a hormetic dose response framework, the recommendations for common terminology are employed to facilitate better understanding and communications between different disciplines and illumination of common molecular survival tools $\mathrm{s}^{[2]}$. Hormesis is an adaptive response characterized by biphasic dose response patterns that at low doses enhances the ability of the cells or organism to withstand more severe stress or compensatory biological processes following an initial disruption of homeostasis. The hormetic response is the adaptive stress response ${ }^{[3]}$. Examples of the general pattern of conserved hormetic pathways include those involving heat-shock proteins, antioxidant systems and anti- 
Am. J. Pharm. \& Toxicol., 3 (1): 4-13, 2008

Table 1: Mimetics of environmental hormesis and disease intervention

\begin{tabular}{|c|c|c|c|}
\hline Disease & Hormetic Agents & Hormetic Mimic & Response Benefit \\
\hline Diabetes & Heat, Exercise & $\begin{array}{l}\text { Aminoguanadine } \\
\text { Aminoguanidine } \\
\text { ALT-11,Thiazolium } \\
\text { Carnosine } \\
\text { Metabolic Inhibitors }\end{array}$ & 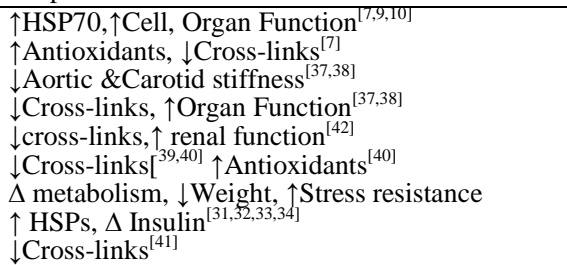 \\
\hline Heart & & & \\
\hline Attack & Heat, Exercise, Ischemia & Ethanol & $\begin{array}{l}\uparrow \text { HSP70, } \uparrow \text { antioxidants, } \\
\downarrow \text { Heart Cell Damage }{ }^{[9,13,15,41]}\end{array}$ \\
\hline Failure & $\begin{array}{l}\text { Cold, Hunger, } \\
\text { Diet Restriction }\end{array}$ & $\begin{array}{l}\text { Hibernation Sera, Deltorphins } \\
\text { ALT-11, Thiazolium } \\
\text { CDRI peptide } \\
\text { Deltorphins }\end{array}$ & $\begin{array}{l}\uparrow \text { Heart Preservation, Survival }{ }^{[55,56]} \\
\uparrow \text { Cross-links, } \uparrow \text { Heart Remodeling } \\
\uparrow \text { Immunoregulators }^{[42,43]} \\
\Delta \text { Metaboart Remodeling } \\
\end{array}$ \\
\hline Hemorrhage & Cold, Hunger, & $\begin{array}{l}\text { Deltorphins } \\
\text { Ischemia }\end{array}$ & $\begin{array}{l}\uparrow \text { Heart Preservation, } \downarrow \text { Acidosis, } \\
\uparrow \text { Metabolic Regulators }{ }^{[58,63,64,65]} \\
\downarrow \text { Inflammatory Response }{ }^{[62]}\end{array}$ \\
\hline Arteriosclerosis & Diet restriction & Angiotensin 2 Receptor Inhibitor & $\downarrow_{\text {Cross-links }}^{[44]}$ \\
\hline Brain Stroke & Ischemia & $\begin{array}{l}\text { DADLE, } \\
\text { Deltorphins } \\
\text { Ethanol }\end{array}$ & $\begin{array}{l}\uparrow \text { Brain Protection }^{[60]} \\
\uparrow \text { Brain Protection }^{[1]} \\
\downarrow \text { Neuronal Death }^{[1]}\end{array}$ \\
\hline Kidney & Ischemia & ALT-11, Thiazolium & $\downarrow$ Cross-links, $\uparrow$ Renal Function ${ }^{[42]}$ \\
\hline Stomach & Ischemia & $\begin{array}{l}\text { ALT-11, Thiazolium } \\
\text { Ethanol }\end{array}$ & $\begin{array}{l}\downarrow \text { Cross-links } \\
\uparrow \text { Mesenteric Artery }^{[12]}\end{array}$ \\
\hline Muscle Wasting & Exercise & $\begin{array}{l}\text { Hibernation mimics } \\
\text { Ethanol }\end{array}$ & $\begin{array}{l}\uparrow \text { Muscle Preservation }^{[50,51,52,54]} \\
\uparrow \text { HSP's }^{[14,15]}\end{array}$ \\
\hline Blood Pressure (BP) & Diet Restriction & $\begin{array}{l}\text { Thiazolium, Biguanides, } \\
\text { Angiotension II Receptor Inhibitor }\end{array}$ & $\downarrow$ Cross-links, $\downarrow \mathrm{BP}^{[31,32,33,34,35,36,42,43,44,45]}$ \\
\hline Cancer & Radiation & $\begin{array}{l}\text { Small Nucleotides, } \\
\text { UV Damage Products }\end{array}$ & $\begin{array}{l}\uparrow \text { DNA repair, } \uparrow \text { Antioxidants }{ }^{[27]} \\
\downarrow \text { Cancer, } \downarrow \text { Aging } \\
\end{array}$ \\
\hline $\begin{array}{l}\text { Alzheimer's } \\
\text { CR }\end{array}$ & $\begin{array}{l}\text { Heat } \\
\text { Thiazolium }\end{array}$ & Ethanol & $\begin{array}{l}\uparrow \text { HSP's, } \downarrow \text { Neuronal Death }{ }^{[10]} \\
\text { Maybe } \downarrow \text { Cross-links, } \downarrow \text { Inflammation }{ }^{[42,43]}\end{array}$ \\
\hline
\end{tabular}

Table 2: Hormetic Mimetics and Aging Intervention

Longevity Conserved Determinants Hormetic Mimetic Candidate Agents

Genetic Stability

Metabolic Control

Oligonucleotides induce latent DNA repair, epigenetic modifiers, antioxidants, and tumor suppressors. Cross-link inhibitors \& breakers. CR and Weight Loss Drugs, to repress some age-related changes, alter damage, and delay aging. Caloric Restriction alters cell metabolism and the insulin/IGF-1 pathway, and delays damage from reactive oxygen species. Biguanides and Thiozolium can be used as CR mimetics. Ethanol can induce HSP's to repair age-damaged proteins. Ethanol and Carnosine can absorb cross-linking agents to reduce age-related altered proteins and their associated changes in cell, organ, and disease susceptibility including cancer, Alzheimer's, kidney, brain, and cardiovascular diseases. Hibernation Mimetics, Deltorphins, may be useful since they can alter metabolism under stress.

Stress Resistance Oligonucleotides trigger $\uparrow$ age-suppressed DNA repair, endogenous antioxidant defenses, HSP's, and signal transduction pathways. The age-related increase in oxidized DNA and proteins can be delayed. Hibernation Mimetics, Deltorphins, alter the response to stress and increase survival to stress and are proposed here as anti-aging candidates.

Immunoregulators CDR1, an ancient peptide, is an effective regulator of immune response in mammals and can reverse immunosenescence.

apoptotic pathways ${ }^{[4]}$. Here, the review focuses on hormetic mimetics of heat, radiation, caloric restriction, immunoregulators and hibernation for their potential use in anti-aging, disease and trauma. The review focuses on elucidating common pathways that delay age-associated diseases and promote longevity using mimetics of known hormetic signals (Table 1,2).

\section{HEAT: PHYSIOLOGICAL CONDITIONING HORMESIS, ETHANOL MIMETIC}

The classic stress response includes two groups of stress responsive proteins divided into two groups: those referred to as heat shock proteins induced by nonphysiological exposure to heat and those called the glucose-regulated proteins that exhibit synthesis when cells are deprived of glucose, oxygen, or disruption of calcium homeostasis ${ }^{[5]}$. Since heat-induced thermotolerance is characterized in a wide range of organisms from Eschericia coli to Homo sapiens, this response is a biologically significant survival strategy conserved throughout evolution. The potential of heat as a strategy for intervention in aging and related diseases was recently reviewed ${ }^{[6]}$.

The expression of heat shock proteins is regulated primarily at the transcription level by the binding of a 
protein called the heat shock factor (HSF) to a conserved DNA sequence in the promoter of all inducible heat shock genes to provide a coordinated cascade of novel gene expression. A major role for the induced heat shock HSP70 family is in chaperoning the refolding of denatured protein, which can restore protein function regardless of the denaturing agent, be it from chemical, environmental, or age related stress. Higher doses of the stressing agent, on the other hand, can overload the system and result in uncontrolled degradation of necessary regulatory molecules like hormetic agents. Elevated temperature has been shown to increase lifespan in human fibroblasts and keratinocytes $^{[6,7,8]}$. The heat treatment increased the basal levels of various chaperones, reduced the accumulation of damaged proteins, stimulated proteasomal activities for the degradation of abnormal proteins, improved cellular resistance to ethanol, hydrogen peroxide, UV-B rays, enhanced the levels of various antioxidant enzymes and increased the phosphorylation-mediated activities of various stress kinases. The effect of combination of heat and potential hormetic molecules, such as curcumin, on aging, longevity and differentiation of human cells in culture is under investigation ${ }^{[7]}$. Stress response genes, particularly HSP70, are now the major candidates in the gene-longevity association studies ${ }^{[8]}$. A potential mimetic of heat hormesis is ethanol. Constitutive and inducible HSP70s are involved in oxidative resistance evoked by heat shock and ethanol ${ }^{[9]}$. In the brain, moderate ethanol pretreatment causes an almost 3-fold increase in brain levels of heat shock protein 70 (HSP70) and can prevent beta-amyloid peptide (Abeta)induced neurotoxicity and apoptosis in organotypic hippocampal-entorhinal slice cultures and suggest possible molecular mechanisms underlying the protective effect of moderate drinking against Alzheimer's dementia ${ }^{[10]}$. Prior ingestion of ethanol in gerbils ameliorated behavioral deficit induced by cerebral Ischemia/Reperfusion (IR) and protected the brain against I/R-induced delayed neuronal death, neuronal and dendritic degeneration, oxidative DNA damage and glial cell activation ${ }^{[11]}$. In the heart, heat inducible HSP70 (HSP70i) has a known cardioprotective effect against I/R injury. Ethyl alcohol evoked a similar pattern of $\mathrm{H}_{2} \mathrm{O}_{2}$ resistance, HSP induction and distribution using rat myocytes ${ }^{[9]}$. In the stomach, ethanol pretreatment induces a biphasic temporal pattern of protection against the proinflammatory effects of I/R of the mesenteric artery and the reactive oxygen species triggers the development of an anti-inflammatory phenotype and resistance 24 h later ${ }^{[12]}$.
The cardioprotective advantage of moderate consumption of ethanol in popular beverages the socalled French Paradox may result from ethanol induced favorable changes in lipid metabolism, antioxidant effects, changes in hemostasis and platelet aggregation, arterial vasodilatation mediated by NO release, expression of cardioprotective proteins, insulin sensitization and lower levels of inflammatory markers. Some of the compounds present in red and white wine, such as resveratrol and quercetin, are also partly responsible for some of the cardioprotective effects of alcoholic drinks. These are due to antioxidant effects and changes in platelet aggregation, endothelial function and inflammatory response ${ }^{[13]}$.

Threshold levels of exercise can induce heat HSP70 and can parallel the beneficial effects of heat as a hormetic agent ${ }^{[14,15]}$ and ethanol, under appropriate conditions, may provide some of the benefits of exercise.

\section{RADIATION HORMESIS: PHYSIOLOGICAL CONDITIONING HORMESIS, OLIGONUCLEOTIDE AND OTHER CHEMICAL MIMETICS}

Radiation hormesis has been shown to increase life span in numerous model systems ${ }^{[16,17,18]}$. When Paramecium cells were exposed to ultraviolet radiation and photoreactivation repair, a $296 \%$ increase in remaining life span was found suggesting activation of reserve repair ${ }^{[18]}$, a major evolutionarily conserved longevity assurance loci ${ }^{[19]}$. UV-induced repair by low dose irradiation in mammalian cells has been shown to include enhanced repair rate for subsequent DNA damage in repair proficient and deficient cells by an evolutionary conserved protective adaption to DNA damage $^{[20]}$. A UV irradiation mimetic, thymine dinucleotide, in human skin cells results in upregulation of DNA repair genes stimulated by the p53 transcription factor and tumor suppressor. The human cell damage response includes melanogenesis (tanning), transient immunosuppression, resistance to subsequent radiation and antioxidant enzymes ${ }^{[21,22,23,24]}$. The oligonucleotide-UV- mimetic provides orchestration of major longevity assurance repair loci. The age-related increased mutation rate, reduced DNA repair and increased cancer, which appear to be due to slow basal levels of repair, can be restored to youthful levels by induction of a latent repair system by the UV chemical hormetic agent, thymidine dinucleotide, an obligate substrate for UV damage and for induced repair ${ }^{[21]}$. These topical DNA oligonucleotides have been shown to reduce UV mutagenesis and photocarcinogenesis in mice $^{[22,23,24]}$. 
Another candidate chemical hormetic UV mimetic is an oligonucleotide sequence of the telomere 3' strand (T-oligos) which triggers expression of a subset of genes for repair in normal cells ${ }^{[25]}$. Telomeres are known to be involved in the limited cell division potential of specific cells. T-oligos stimulated the induction type II programmed cell death and may function as agents to destroy cancer cells.

Interestingly, fibroblasts from patients with the premature aging syndrome, WRS, were unable to initiate DNA damage signaling and formation of DNA damage foci following T-oligo stimulation, in contrast to normal cells implicating the Werner protein in this signaling ${ }^{[25,26]}$. The inability for induction of DNA repair is a symptom in this premature aging disease.

In general, T-oligos represent chemical agents that can mimic environmental radiation hormesis and can have tremendous potential for intervention in aging and cancer.

An alternative approach, which could be used in combination with T-oligos, is chemical agents known to induce endogenous antioxidants that can protect cells from UV induced oxidative damage. DNA damages, induced by UVA or UVB, are significantly reduced by the presence of chemical hormetic agents, thiol molecules, selenium and zinc ${ }^{[27] .}$. These radiation mimetics primarily elevate DNA repair and endogenous antioxidants, both recognized conserved stress resistance pathways that are anti-aging, intervene in carcinogenesis and preserve cell and tissue function. Since exercise can elevate antioxidant pathways ${ }^{[28]}$, exercise should provide some protection against radiation damage. Diseases and age related disorders related to oxidative and DNA damage should benefit from $\mathrm{T}$ oligo treatment in the absence of radiation by up-regulation of endogenous stress resistance pathways.

\section{DIET RESTRICTION: RECOGNITION OF ANTIGLYCATION AS POSTEXPOSURE CONDITIONING HORMESIS}

Data from yeast, worms, flies and mammals indicate that Caloric Restriction (CR) is not simply a passive effect, but an active, highly conserved response to stress, which increases survival in adverse conditions and is involved with central and peripheral effects of the Insulin/IGF-1 signaling in aging and cancer ${ }^{[29]}$. Changes in body weight (or CR) alter the response of an organism to chemical and physical agents and can improve their ability to withstand chemical and physical challenges ${ }^{[30]}$. Pharmaceutical- mimetics which could produce the beneficial health-promoting and antiaging effects of caloric restriction even if only partial benefit range from glycolytic inhibitors, lipid regulating agents, antioxidants, sirtuin regulators, autophagic enhancers, insulin specific gene modulators and weight loss drugs ${ }^{[31,32,33]}$. Candidate $\mathrm{CR}$ mimetics used in treatment of diabetics have been effective in eliciting positive metabolic changes among the biguanides, but toxic side effects can accompany some candidate mimetics $^{[31,33,34]}$. Exercise can be a dramatic hormetic conditioner that can promote weight loss and provide the associated weight loss CR benefits.

Another class of CR mimetics, which can intervene in inappropriate protein cross-links, is antiglycation agents. CR has been found to reduce the extent of glycation of blood and tissue proteins and the agerelated accumulation of glycoxidation products in skin collagen $^{[35]}$. Accelerated formation of advanced glycation/lipoxidation and endproducts (AGEs/ALEs) are implicated in multiple disease states including the pathogenesis of various diabetic complications, ischemic heart disease and neurodegenerative diseases $^{[35,36]}$. Glycation products undergo progressive modification over time, in vivo, to form irreversible AGE cross-links. Intervention in toxic glycation products before, during, or after their formation, in the absence of diet restriction, is under active investigation. Mimetics are known to inhibit, repair (break)/and or absorb (stabilize intermediate in the cross- link progression) glycation products and avoid the age and disease related consequences without diet restriction.

Physiological conditioning- hormetic agents include aminoguanide, carnosine, ethanol and angiotension II receptor inhibitors. Aminoguanidine, an inhibitor of AGE formation, has been shown to prevent increases in aortic and carotid arterial wall stiffness in diabetic rats ${ }^{[37,38]}$. Carnosine, a dipeptide natural neuropeptide, seems to inhibit glycation and even target glycated proteins for removal ${ }^{[39]}$. Carnosine is readily glycosylated non-enzymatically upon incubation with the sugars glucose, galactose, deoxyribose and the triose dihydroxyacetone. Carnosine also inhibits glycation of acetyl-Lys-His-amide by dihydroxyacetone and protected alpha-crystallin, superoxide dismutase and catalase against glycation, thereby preserving a natural antioxidant. Cross-linking mediated by ribose, deoxyribose, dihydroxyacetone, dihydroxyacetone phosphate and fructose was inhibited. Carnosine prevents oxidation and protein modification, decreased carbonyls, lipid peroxides and improves age related behavior $^{[40]}$.

Ethanol can significantly reduce hemoglobin Amadori products that are intermediates in the cascade of cross-linking of proteins in diabetic rats. Ethanol is metabolized to acetaldehyde, a two-carbon carbonyl 
compound that can react with nucleophiles to form covalent addition products. A biochemical modification produced by the reaction of acetaldehyde with proteinbound Amadori products stabilizes the intermediates ${ }^{[41]}$ and therefore acts as a sponge for the cross-linking agents.

Postexposure conditioning hormesis can ameliorate the inappropriate cross-links associated with diabetes and aging in the absence of diet restriction. Thiazolium derivatives, function as cross-link breakers, cleave the inappropriate glucose- formed cross-links and restore tissue proteins as effective physiological postexposure conditioning hormetic agents rejuvenating cells, tissues and organs. ALT-711, an AGE related collagen crosslink breaker was found to improve diastolic heart function in elderly patients, increase ventricular function, decreased ventricular collagen content and improved its solubility, reduced aortic stiffness, ameliorated diabetic nephrosclerosis and improved renal function ${ }^{[42]}$. The effects of cross-links breakers may be mediated in part via reduction in oxidative stress and profibrotic cytokines ${ }^{[43]}$. Restoration of normal structure would retard the body's normal inflammatory responses to abnormal structures and thus to inflammatory diseases like atherosclerosis.

Blockade of angiotensin II receptors as well reduces the expression of receptors for advanced glycation end products in human endothelial cells ${ }^{[44]}$ and provides physiological conditioning hormesis. Thiazolium is known to induce cytochrome P450 in rodents and hepatic cells ${ }^{[45]}$ suggesting alteration of gene expression in the pathway of cross-linking-breaker benefit. The inhibition of glycation, repair of crosslinked molecular structures and induction of protective cellular environments all offer therapeutic options for reducing glycation without diet restriction. Antiglycation intervenes in multiple age-related pathologies of circulatory, nervous and excretory systems as well as inflammatory related diseases. Accumulation of inappropriate cross-link results in impaired function. The broad scope of intervention-benefit from breaking glucose related protein cross-links implicates glucose in the aging process and a rationale for the benefit of diet restriction in aging and diabetes-acceleration of agerelated diseases.

\section{IMMUNOLOREGULATORS AS POSTEXPOSURE PHYSIOLOGICAL CONDITIONING HORMESIS: CONSERVED PEPTIDES}

An example of a preserved ancient immune response, which can be activated in higher organisms, is
$\mathrm{T}$ cell immunoregulation ${ }^{[46]}$. Sharks are the lowest vertebrates to possess the genes essential for mounting the adaptive or combinatorial immune response against a wide set of antigens involved in homeostasis, immunoregulation and response to infection ${ }^{[47]}$. All three-shark species possess constitutive antibodies to shared idiotypes defined by the CDR1 segment of the T cell receptor beta chain variable domain ${ }^{[47,48]}$. Relative amounts of these autoantibodies vary with aging, pregnancy, allografts and retroviral infection. Suppression of mammalian immunity, especially TH1type helper $\mathrm{T}$ cells, is a consequence of retroviral infection, the normal aging process and accelerated by autodestructive diseases ${ }^{[46]}$. There is an antagonistic role of spontaneously arising autoantibodies to $\mathrm{T}$ cell receptor TCR domains and TCR V B derived peptide epitopes, in maintaining the balance of TH1 and TH2type immunity. It was discovered that certain TCR $\mathrm{Vb}$ CDR1 peptides can reverse the negative effects of immunosenescence on normal TH1 and TH2 T cell subsets and restore resistance to cardiopathology in mice. The TCR peptide itself restores balance between TH1 and TH2 cells and stimulated cell remodeling defective heart tissue. A role for cell immunity is implied in cardiac repair ${ }^{[49]}$. Net collagen synthesis was increased via downregulation of matrix metalloproteinase, altered fibroblast expression and enzymatic activity. TH activity could promote adaptive remodeling in heart failure patients and in patients with damaged cardiac tissue after a heart attack. Coordination of self versus non-self recognition is related to $\mathrm{T}$ and $\mathrm{B}$ lymphocytes $\mathrm{T}$ cell receptor recognition. The natural regulation of the immune system might be harnessed by administration of the ancient shark peptides (CDR1) to stimulate healing in patients whose immune system is suppressed. There is an adaptive role of $\mathrm{T}$ cells from peptide treated mice in remodeling damaged hearts by increasing net collagen synthesis by cardiac fibroblasts. Thus postexposure physiological conditioners may be able to restore heart function in the aged population who show aging decline of the immune system using a peptide conserved from sharks to man.

\section{HIBERNATION INDUCTION TRIGGER MIMETIC: DELTA OPIOID RECEPTOR AGONISTS}

Hibernation is a well-known biological strategy used to tolerate stress. The hibernating animal tolerates the stress of depleted energy stores, intracellular acidosis, hypoxia, hypothermia, cell volume shifts and can resist muscle wasting ${ }^{[50,51,52]}$. Hibernation Induction 
Trigger (HIT), was reported to be an 88 residue opioidlike peptide ${ }^{[53]}$ and serum from hibernating woodchucks protected skeletal muscles from hypoxia/reperfusion injury $^{[54]}$ and was cardioprotective when used as a physiological conditioning hormetic agent ${ }^{[55,56]}$.

Mimetics of HIT have been found to be effective in both physiological conditioning and postexposure conditioning hormesis. Two major HIT candidate mimetics are the delta opioid receptor agonists, DADLE [D-Ala(2)-D-Leu(5)-Enkephalin] and deltorphin variants. The dose-response curves of antiapoptotic effects of DADLE are U-shaped as judged by biochemical or morphological assays in rat adrenal tumor cells in physiological conditioning studies ${ }^{[57]}$. Deltorphin E (DeltE) exhibits a stimulatory beneficial low dose range and toxic high dose effects ${ }^{[58]}$ exhibiting patterns consistent with postexposure conditioning hormesis. DADLE induced hibernation-like changes in mammalian HeLa cells ${ }^{[59]}$ and protected starvation of serum-deprived rat tumor PC12 cells ${ }^{[59]}$. DADLE is protective against neurotoxins, ameliorates the neuronal damage induced by ischemia-reperfusion following a transient middle cerebral artery occlusion and activates the beneficial recompensatory phase ${ }^{[60]}$.

Deltorphins, which are HIT mimetics, induce multiple beneficial responses. Deltorphins are found in epidermal secretions of Phyllomedusa bicolor, a South American frog which is used topically by Peruvian tribes for increased physical strength, heightened senses, resistance to hunger, thirst and promotion of fearless emotion, when used before a hunt ${ }^{[61]}$. Deltorphin Dvar (Tyr-d-Ala-Phe-Ala-Asp-Val-Ala-SerThr-Ile-Gly-Asp-Phe-Phe-His-Ser-Ile-NH2), a $\quad \delta_{2}$ specific receptor agonist, as well as the HIT-Winter containing blood serum pretreatment, conferred physiological conditioning hormesis exhibited by cardioprotection in rodents and swine ${ }^{[55,56]}$. DeltDvar but not DADLE, could inhibit LPS proinflammatory cytokine production by macrophages and suppress LPSinduced p38 MAPK activation and expression of TNFalpha and MIP-2 ${ }^{[62]}$ suggesting an antiinflammatory effect of these peptides.

Postexposure physiological conditioning hormesis with DeltDvar facilitates recovery from moderate $(\sim 30 \%)$ hemorrhage after blood pressure crash in conscience rats ${ }^{[63]}$. Alteration of the peripheral nervous system was suggested by a change in baroreflex sensitivity. Thus, recovery of Mean Arterial Pressure (MAP) and Heart Rate (HR) was facilitated. By resetting baroreflex sensitivity, animals are able to respond to decreases in arterial pressure by increasing heart rate after moderate hemorrhage ${ }^{[63]}$. DeltDvar also stimulates effective physiological conditioning hormesis. Treatment $24 \mathrm{~h}$ prior to hemorrhage facilitates recovery from severe ( $53 \%$ total blood loss) hemorrhagic shock during the recompensatory phase by improving hemodynamic stability and survival ${ }^{[64]}$. Delta Dvar-induced MAP recovery was correlated with retardation of the anaerobic glycolytic pathways as seen by reduced lactic acidosis. The metabolic depression is similar to that seen in hibernation and may also involve inhibition of nitric oxide toxicity ${ }^{[65]}$.

Another HIT mimetic, DeltE, (Tyr-D-Ala-Phe-AlaIle-Gly-Asp-Phe-Ser-Ile-NH2), within a stimulatory dose range, restores hemodynamic stability after severe hemorrhage $(\sim 50 \%)$ treatment without fluid resuscitation using behaving rodents ${ }^{[58]}$ when used as a postexposure physiological conditioning agent. Our recent studies showed this peptide was effective in maintenance of Mean Arterial pressure, increased post hemorrhage survival time, alteration of pulse pressure (difference between systolic and diastolic blood pressure) and reduced mean lactic acid levels indicating metabolic depression similar to that seen in hibernation. The role of pulse pressure in ischemic stress response has not been fully characterized, but enhancement of pulse pressure can act as a treatment of hypoperfusion in shock ${ }^{[66]}$. In humans, it is known that exerciseinduced stress, can alter pulse pressure that increase stroke volume and cardiac output leading to greater tissue profusion ${ }^{[67]}$. The dose dependent reduction of lactic acid acidosis predicted survival time ${ }^{[58]}$ and may be a candidate for combination with anti-diabetic drugs to provide stable metabolic states. Evidence for metabolic regulation during hibernation was found in hibernating bears. Protein synthesis and breakdown were both lower in winter compared to summer but were equal during both early and late denning, indicating that bears are in protein balance during hibernation in the anorexic state ${ }^{[52]}$.

Thus, mimetics of HIT, DADLE, DeltDvar and DeltE can elicit physiological conditioning or postexposure physiological conditioning hormesis. The mechanisms of the conditioning responses are not yet fully characterized but are dependent on the extent of severity and the specific mimetic used and its mechanism of action. These opioids provide a potent potential for use in emergency trauma setting, i.e., in wartime, natural disasters, accidents, or in anticipated critical surgical procedures with risks of ischemic stress. Combination with other hormetic agents can activate different beneficial adaptive cascades to promote survival and repair.

Opioid mimetics may also provide the cardioprotective effects of exercise against ischemia/reperfusion damage since these opioids can 
activate central and peripheral neuronal responses that could amplify the known exercise induced heat shock and antioxidant benefits ${ }^{[15,25,67]}$.

The ability of deltorphins as hibernation mimics to modify metabolic and neuronal controls to tolerate stress when challenged by moderate and severe trauma suggests these agents as candidate anti-aging hormetic conditioners especially in heart attack and stroke damage, but perhaps also as a mimic of Caloric Restriction.

\section{CONCLUSION}

The plethora of unique age-associated diseases and their functional deficits have common bases in altered DNA gene expression and protein structure that can be at least partially restored by hormetic triggers. In summary, chemical mimetics of the beneficial effects of hormesis from heat, radiation, diet restriction, cold and hunger, are effective inducers of stress resistance without exposure to the environmental stressing agent (Table 1). The mimetics reviewed here are small nucleotide SOS signals, dipeptides, ethanol, thiols and metals and conserved peptide sequences found in sharks, frogs, woodchucks and bears which regulate cytokines, cellular immunity, central and peripheral neuronal regulatory pathways for blood pressure maintenance, heart rate, metabolic pathways and age related disease sensitivity by activation of latent protective protein and DNA mechanisms (Table 2). The hibernation mimetics, which improve tolerance to ischemic stress, and alter metabolism, offer new potential in anti-aging strategies. Combination of agents is an emerging strategy for disease prevention. Stimulation of protein repair associated with heat shock proteins by chaperone refolding of denatured proteins, restoration of cytoskeleton, enzymatic ability, waste protein removal, rejuvenated vasculature by cross-link breakers, stimulated DNA repair, and activated antioxidant and immune defenses are all hormetic mimetic responses found. The resultant mimeticinduced physiological environment provides resistance to the same or cross-reacting different stressors that can rejuvenate age-damaged cells, reverse or retard disease states and intervene in trauma. Hormetic mimetics are the promise of now and the future for intervention into aging, carcinogenesis, diseases and trauma. The investigation into the hormetic effects of environmental stress has led us to imitate-and if necessary to correct and complement-the body's own molecular mechanisms used to combat the stress factor in disease as envisioned by Seyle ${ }^{[1]}$ and discovered by following the path of low doses of otherwise harmful agents. The pioneering and championing efforts of Calebrese and colleagues to recognize and understand the non-linear response in toxicology has led us to these most promising pathways for preventing and interfering in stress related disorders, regardless of the inciting agent.

\section{REFERENCES}

1. Seyle, H., 1946. The general adaptation syndrome and the disease of adaptation. J. Clin. Endocrinol., 6: 117-230.

2. Calabrese, E.J., K.A. Bachmann, A.J. Bailer, P.M. et al., 2007. Biological stress response terminology: Integrating the concepts of adaptive response and preconditioning stress within a hormetic dose-response framework: Review. Toxicolol. Applied Pharmacol., 222 (1): 122-128.

3. Smith Sonneborn, J., 1992. Overview lecture. The role of the stress protein response in hormesis. In: Low Dose Irradiation and Biological Defense Mechanisms. Sugahara, T., L.A. Sagan and T. Aoyama, (Eds.). pp: 399-404. Excerpta Medica. Elsevier, Amsterdam.

4. Arumugam, T.V., M. Gleichmann, S.C. Tang and M.P. Mattson, 2006. Hormesis/preconditioning mechanisms, the nervous system and aging: Review. Ageing Res. Rev., 5 (2): 165-178.

5. Morimoto, R.J., 2006. Stress, aging and neurodegenerative disease: Review. The New England J. Medicine, 355 (21): 2254-2255.

6. Pierpaoli, E., 2005. The role of HSP70 in agerelated diseases and the prevention of cancer: Review. Ann. of the New York Academy of Sciences, 1057: 206-19.

7. Rattan S.I. and R.E. Ali, 2007. Hormetic prevention of molecular damage during cellular aging of human skin fibroblasts and keratinocytes: Review. Ann. of the New York Academy of Sciences, 1100: 424-430.

8. Singh, R., Kolvraa, S. and S.I. Rattan, 2007. Genetics of human longevity with emphasis on the relevance of HSP70 as candidate genes: Review. Frontiers in Bioscience, 12: 4504-4513.

9. Su, C.Y., K.Y Chong, O.E. Owen, W.H. Dillmann, C. Chang and C.C. Lai, 1998. Constitutive and inducible HSP70s are involved in oxidative resistance evoked by heat shock or ethanol. J. Mol. Cellular Cardiol., 30 (3): 587-98.

10. Belmadani A.S., S. Kumar, M. Schipma, M.A. Collins and E.J. Neafsey, 2004. Inhibition of amyloid-beta-induced neurotoxicity and apoptosis by moderate ethanol preconditioning. Neuroreport, 15 (13): 2093-2096. 
11. Wang, Q., A.Y. Sun, A. Simonyi, T.J. Kalogeris, D.K. Miller, G.Y. Sun and R.J. Korthuis, 2007. Ethanol preconditioning protects against ischemia/reperfusion-induced brain damage: Role of NADPH oxidase-derived ROS. Free Radi. Biol. Med., 43 (7): 1048-60.

12. Yamaguchi, T., C. Dayton, T. Shigematsu, P. Carter, T. Yoshikawa, D.C. Gute and R.J. Korthuis, 2002. Preconditioning with ethanol prevents postischemic leukocyte-endothelial cell adhesive interactions. Am. J. Physiol., Heart Circulatory Physiol., 283 (3): H1019.

13. Providencia, R., 2006. Cardiovascular protection from alcoholic drinks: Scientific basis of the french paradox: Review. Portuguese J. Cardiol., 25 (11): 1043-1058.

14. Smith Sonneborn, J. and S. Barbee, 1998. Exercise-induced stress response as an adaptive tolerance strategy. Environ. Health Perspec., 106: 325-330.

15. Sakamoto, M., T. Minamino, H. Toko, Y. Kayama, Y. Zou, M. Sano, E. Takaki, T. Aoyagi, K. Tojo, N. Tajima, N.A. Nakai, H. Aburatani and I. Komuro, 2006. Upregulation of heat shock transcription factor 1 plays a critical role in adaptive cardiac hypertrophy. Circulation Res., 99 (12): 1411-1418.

16. Pollycove, M. and L.E. Feinendegen, 2001. Biologic responses to low doses of ionizing radiation: Detriment versus Hormesis. Part II. Dose responses of organisms. J. Nuclear Med., 42: 26-37.

17. Sonneborn, J. 2005. The myth and reality of reversal of aging by hormesis. Annals of the New York academy of sciences, 1057: 165-176.

18. Smith Sonneborn, J., 1979. DNA Repair and Longevity Assurance in Paramecium tetraurelia. Science, 203: 1115-1117.

19. Hart, R.W. and R.B. Setlow, 1975. DNA repair and life span of mammals, basic life sciences. 5: 80-84.

20. Eller, M.S., T. Maeda, C. Magoni, D. Atwal and B.A. Gilchrest, 1997. Enhancement of DNA repair in human skin cells by thymidine dinucleotide: Evidence for a p53 mediated mammalian SOS response. Proceedings of the National Academy of Sciences of the United States of America, 94: 12627-12632.

21. Arad, S., N. Konnikov, D.A. Goukassian and B.A. Gilchrest, 2007. Quantification of inducible SOS-like photoprotective responses in human skin, 2007. J. Invest. Dermatol., 127 (11): 2629-2636.
22. Arad, S., N. Konnikov, D.A. Goukassian and B.A. Gilchrest, 2006. T-oligos augment UVinduced protective responses in human skin. Federation of Am. Soc. Exp. Biol. J., 20 (11): 1895-1897.

23. Goukassi, D.A., S. Bagheri, L. El-Keeb, M.S. Eller and B.A. Gilchrest, 2002. DNA oligonucleotide treatment corrects the age-associated decline in DNA repair capacity. Federation of Am. Soc. Exp. Biol. J., 16: 754-756.

24. Goukassian D.A., E. Helms, H. van Steeg, C. van Oostrom, J. Bhawan, B.A. Gilchrest, 2004. Topical DNA oligonucleotide therapy reduces uv-induced mutations and photocarcinogenesis in hairless mice. Proceedings of the National Academy of Sciences of the United States of America, 101 (11): 3933-3938.

25. Aoki, H., E. Iwado, M.S. Eller, Y. Kondo, K. Fujiwara, G.Z. Li, K.R. Hess, D.R. Siwak, R. Sawaya, G.B. Mills, B.A. Gilchrest and S. Kondo, 2007. Telomere 3 overhang-specific DNA oligonucleotides induce autophagy in malignant glioma cells. Federation of Am. Soc. Exp. Biol. J., 21: 2918-2930.

26. Eller, M.S., X. Liao, S. Liu, K. Hanna, H.Bäckvall, P.L. Opresko, V.A. Bohr and B.A. Gilchrest, 2006. A role for WRN in telomere-based DNA damage responses. Proceedings of the National Academy of Sciences United States of America, 103 (41): 15073-15078.

27. Beani, J.C., 2001. Enhancement of endogenous antioxidant defenses: A promising strategy for prevention of skin cancers, Bulletin de l'Academie Nationale Medecine, 185 (8): 1507-1525.

28. Hamilton, K.L., 2007. Antioxidants and cardioprotection: Review. Med. Sci. in Sports Exer., 39 (9): 1544-1553.

29. Sinclair, D.A., 2005. Toward a unified theory of caloric restriction and longevity regulation: Review. Mechanisms of Ageing and Development, 126: 987-1002.

30. Turturro, A., B.S. Haas and R.W. Hart, 2000. Does caloric restriction induce hormesis? Review. Hum. Exp. Toxicol., 19 (6): 320-329.

31. Roth, G.S., 2005. Caloric restriction mimetics the next phase: Review: Annals of the New York Academy of Sciences, 1057: 365-371.

32. Lane, M.A., G.S. Roth and D.K. Ingram, 2007. Caloric restriction mimetics: A novel approach for biogerontology: Review. Methods in Molecular Biology, 371: 143-9. 
33. Anisimov, V.N., 2006. Premature ageing prevention: Limitations and perspectives of pharmacological interventions: Review. Current Drug Targets, 7 (11): 1485-1503.

34. Berstein, L.M., I.G. Popovich, M.A. Zabezhinski, P.A. Egormin, M.L. Tyndyk, I.V. Anikin, A.V. Semenchenko and A.I. Yashin, 2005. Central and peripheral effects of insulin/IGF-1 signaling in aging and cancer: Antidiabetic drugs as geroprotectors and anticarcinogens: Review. Annals of the New York Academy of Sciences, 1057: 220-234.

35. Cefalu, W.T., A.D. Bell-Farrow, Z.Q. Wang, W.E. Sonntag, M.X. Fu, J.W. Baynes and S.R. Thorpe, 1995. Caloric restriction decreases age accumulation of the glycoxidation products, $\mathrm{N}$ epsilon-(carboxymethyl) lysine and pentosidine, in rat skin collagen. J. Gerontol. Biol. Sci. Med. Sci., 50 (6): B337-341.

36. Rahbar, S., 2007. Novel inhibitors of glycation and AGE Formation: Review. Cell Biochem. Biophys., 48 (2-3): 147-157.

37. Ulrich, P. and A. Cerami, 2001. Protein glycation, diabetes and aging: Review. Recent Progress in Hormone Res., 56: 1-21.

38. Norton, G.R., G. Candy and A.J. Woodiwiss, 1996. Aminoguanidine prevents the decreased myocardial compliance produced by streptozotocin-induced diabetes mellitus in rats. Circulation, 93: 1905-1912.

39. Hipkiss A.R., J. Michaelis and P.J, Syrris, 1995. Non-Enzymatic glycosylation of the dipeptide Lcarnosine, a potential anti-protein-cross-linking agent. Federation of the European Biological Science Letters, 371 (1): 81-85.

40. Boldyrev, A.A., 2005. Protection of proteins from oxidative stress a new illusion or a novel strategy: Review. Annals of the New York Academy of Sciences, 1057: 193-205.

41. Al-Abed, Y., T. Mitsuhashi, H. Li, J.A. Lawson, G.A., FitzGerald, H. Founds, T. Donnelly, A. Cerami, P Ulrich and R. Bucala, 1999. Inhibition of advanced glycation endproduct formation by acetaldehyde: Role in the cardioprotective effect of ethanol: Review. Proceedings of the National Academy of Sciences of the United States of America of the United States of Anmeica, 96 (5): 2385-2390.

42. Little, W.C., M.R. Zile, D.W. Kitzman, W.G. Hundley, T.X. O'Brien, R.C. Degroof, 2005. The effect of alagebrium chloride (ALT-711), A novel glucose cross-link breaker, in the treatment of elderly patients with diastolic heart failure. J. Cardiac Failure, 11 (3): 191-195.
43. Susic, D., J. Varagic, J. Ahn and E.D. Frohlich, 2004. Crosslink breakers: A new approach to cardiovascular therapy. Curr. Opin. Cardiol., 19 (4): 336-340.

44. Fujita, M., H. Okuda, O. Tsukamoto, Y. Asano Y. L. Hirata, J. Kim, T. Miyatsuka, S. Takashima, T. Minamino, H. Tomoike and M. Kitakaze, 2006. Blockade of angiotensin II reduces the expression of receptors for advanced glycation end products in human endothelial cells. Arteriosclerosis, Thrombosis and Vascular Biol., 26 (10): 138-142.

45. Lee, I.J., K.S. Jeong, B.J. Roberts, A.T. Kallarakal, P. Fernandez-Salguero, F.J. Gonzalez and B.J. Song, 1996. Transcriptional induction of the cytochrome P4501A1 gene by a thiazolium compound, YH439. Mol. Pharmacol., 49 (6): 980-988.

46. Marchalonis, J.J., S.F. Schulter, R.T. Sepulveda, R.R. Watson and D.F. Larson, 2005. Immunomodulation by immunopeptides and autoantibodies in aging, autoimmunity and infection: Review. Annals of the New York Academy of Sciences, 1057: 247-259.

47. Marchalonis, J.J., S.F. Schulter, R.M. Bernstein, S. Shen and A.B. Edmundson et al., 1998. Phylogenetic emergence and molecular evolution of the immunoglobin family: Review. Advances in Immunology, 70: 417-506

48. Adelman, M.K., S.F. Schulter and J.J. Marchalonis, 2004. The natural antibody repertoire of sharks and humans recognizes the potential universe of antigens. Protein J., 23: 103-118.

49. Yu, Q., R.R. Watson, J.J. Marchalones and D.F. Larson, 2005. A role for $\mathrm{T}$ lymphocytes in mediating cardiac diastolic function. Am. J. Physiol., Heart Circulation Physiol., 289: 643-651.

50. Harlow, H.J., T. Lohuis, T.D. Beck and P.A. Iaizzo. 2001. Muscle strength in overwintering bears. Nature, 409: 997.

51. Lohuis, T.D., H.J. Harlow, T.D. Beck and P.A. Iaizzo, 2007. Hibernating bears conserve muscle strength and maintain fatigue resistance. Physiol. Biochem. Zool., 80 (3): 257-269.

52. Lohuis T.D., H.J. Harlow and T.D. Beck, 2007. Hibernating bears (Ursus Americanus) experience skeletal muscle protein balance during winter anorexia. Comparative Biochemistry and Physiology. Part B Biochemistry and Molecular Biology, 147: 20-28. 
53. Horton, N.D., D.J. Kaftani, D.S. Bruce, E.C. Bailey, A.S. Krober, J.R. Joanes, M. Tucker, N. Khattar, Y/P/ Su, S.F. Bolling and P.R. Oeltgen, 1998. Isolation and partial characterization of an opioid-like $88 \mathrm{kDa}$ hibernation-related protein. Comparative Biochemistry and Physiology, Part B Biochem. Mol. Biol., 119: 787-805.

54. Hong, J., D. C.Sigg, J. A. Coles Jr., P. R. Oeltgen, H. J. Harlow, C.L. Soule and P.A. Iaizzo, 2005. Hibernation induction trigger reduces hypoxic damage of swine skeletal muscle. Muscle and Nerve, 32 (2): 200-207.

55. Smith Sonneborn, J., H. Gottsch, E. Cubin, P. Oeltgen and P. Thomas, 2004. Alternative strategy for stress tolerance: Opioids. J. Gerontol., 59: 433-440.

56. Sigg, D., J.A. Coles Jr, P.R. Oeltgen and P.A. Iaizzo, 2002: Role of $\delta$-opioid receptor agonists on infarct size reduction in swine. Am. J. Physiol., Heart and Circulatory Physiol., 282: H1953-H1960.

57. Hayashi, T., L.I. Tsao and T.P. Su, 2002. Antiapoptotic and cytotoxic properties of delta opioid peptide [D-Ala(2),D-Leu(5)]enkephalin in PC12 cells, Synapse 43(1): 86-94.

58. Rutten, M.R., M. Govindaswami, P. Oeltgen and J. Smith Sonneborn. 2008. Post treatment with the novel deltorphin $-\mathrm{E}$, a $\delta 2$ opioid receptor agonist, increases recovery and survival after severe hemorrhagic shock in behaving rats. Shock, 29: 42-48.

59. Vecchio, L., C. Soldani, M.G. Bottone, M. Malatesta, T.E. Martin, L.I. Rothblum, C. Pellicciari and M. Biggiogera, 2006. DADLE induces a reversible hibernation-like state in hela cells. Histoche. Cell Biol., 125 (1-2): 193-201.
60. Borlongan, C.V., Y. Wang and T.P. Su, 2004. Delta opioid peptide (D-Ala 2, D-Leu 5) enkephalin: Linking hibernation and neuroprotection. Frontiers in Biosci., 9: 3392-3398.

61. Erspamer, V., G.F. Erspamer, C. Severini, R.L. Potenza, D. Barra and G. Miqnoqna, 1993. Pharmacological studies of sapa from phyllomedusa bicolor skin: A drug used by the peruvian matses indians in shamanic hunting practices. Toxicon, 9: 99-111.

62. Husted, T.L., M. Govindaswami. P.R. Oeltgen, S.M. Rudich and A.B. Lentsch, 2005. A delta2opioid agonist inhibits p38 MAPK and Suppresses activation of murine macrophages. J. Surg. Res., 128 (1): 45-49.

63. McBride, S.M., J. Smith-Sonneborn, P.R. Oeltgen and F. Flynn, 2005. Opioid receptor agonist facilitates mean arterial pressure recovery after hemorrhage in conscious rats. Shock, 23: 264-268.

64. Oeltgen, P.R., M. Govindaswami and D.B. Witzke, 2006. Twenty four hour pretreatment with $\delta$ opioid enhances survival from hemorrhagic academic emergency medicine, 13 (2): 127-133.

65. Musser, J.B., T.B. Bentley, S. Griffith, P. Sharma, J. Karaian and P. Mongan, 2004. Hemorrhagic shock in swine: Nitric oxide and potassium sensitive adenosine triphosphate channel activation, anethesiology, 101: 399-408.

66. Zhao, K.S., 2005. Hemorheologic events in severe shock. Biorheol., 42 (6): 463-477.

67. Starnes, J.W. and R.P. Taylor, 2007. Exerciseinduced cardioprotection: Endogenous mechanisms. Med. Sci. Sports Exer. 39 (9):1537-43. 